\title{
Surgical Implications of Variations and Location of Plantar Arterial Arch: An Anatomical Study
}

\author{
Varalakshmi KL ${ }^{1}$, Khzier Hussain Afroze $\mathrm{M}^{2}$, Sangeeta $\mathrm{M}^{3}$ \\ ${ }^{1}$ Associate Professor, Department of Anatomy, MVJ Medical College \&Research Hospital, Bangalore, ${ }^{2}$ Assistant Professor, Department of Anatomy, MVJ \\ Medical College \&Research Hospital, Bangalore, ${ }^{3}$ Professor \& HOD, Department of Anatomy, MVJ Medical College \&Research Hospital, Bangalore.
}

\section{Abstract}

Introduction: The integrity of various structures of foot is mainly depends on its vascular supply. The foot is supplied by deep plantar arterial arch formed by deep branch of dorsalis pedis artery and lateral plantar artery. So,the detailed knowledge of plantar arterial arch is necessary for advances in surgical reconstruction of foot, which in turn avoids the need for amputation. Subjects and Methods: 40 human feet procured from 20 embalmed cadavers of MVJ Medical College and Research Hospital, Bangalore used for the study. Dissection of foot was carried out and variations in the formation and branching pattern of arch are studied in detail. The results were tabulated and analysed statistically. To measure the topographical location of arch, first the length of foot was measured from tip of second toe and posterior most part of heel using flexible ruler. Depending on the length the foot is divided into 3 equal parts- Anterior, Middle and posterior parts. To know the exact location, the middle part is again divided into three equal parts- anterior middle (AM), intermediate middle (IM), posterior middle (PM). Zone in which arch located was noted down and percentage of each location is calculated. Results: The arches were classified into 6 types as per Adachi's classification.TypeB-10\%,Type C-32.5\%,Type D-27.5\%,Type E-17.5\%,Type F-12.5\%.Type A was absent. In the present study majority of arches were located in the anterior middle portion of foot. Conclusion: The present study will be of great help for reconstructive surgeons, microvascular surgeons and radiologist in the successful outcome of any reconstructive and vascular surgeries.

Keywords: Dorsalis pedis artery, lateral plantar artery, reconstructive surgery, microvascular surgeons, Adachi's classification.

Corresponding Author: Dr Khizer Hussain Afroze M, Assistant Professor, Department of Anatomy, MVJMedical College \&Research Hospital, Bangalore.

Received: December 2019

Accepted: December 2019

\section{Introduction}

The human foot being the complex structure plays a major role in recreational, sporting and occupational activities. The integrity of human foot required to perform these major tasks are mainly depends on its blood supply. ${ }^{[1]}$ The sole is supplied by plantar arch which is an arterial arch found between the third and fourth layers of sole, formed by the anastomosis between the deep plantar branch of dorsalis pedis artery and lateral plantar artery. It gives origin to four plantar metatarsal arteries and lateral digital branch to fifth toe known as fibular plantar marginal artery. ${ }^{[2]}$

Similar to superficial palmar arch of hand, plantar arterial arch also shows variations in turns of its formation, course and branching patterns. The thorough knowledge of these variations are important in case of patients undergoing reconstructive surgeries mainly for chronic arterial occlusive diseases to prevent the amputation of foot due to gangrenes. $^{[3]}$

Adachi in 1928 has classified the plantar arterial arch into 6 types based on the formation and branching pattern.

Type A: Main contribution of arch is by deep branch of dorsalis pedis artery. It gives 1-4 plantar metatarsal arteries and fibular plantar marginal artery.

Type B: Deep branch of dorsalis pedis artery gives 1-4 plantar metatarsal arteries and fibular plantar marginal artery is by lateral plantar artery. The anastomosis of two arteries is between $4^{\text {th }}$ plantar metatarsal artery and fibular plantar marginal artery.

Type C: Deep branch of dorsalis pedis artery gives 1-3 plantar metatarsal arteries and lateral plantar artery gives 4th plantar metatarsal artery and fibular plantar marginal artery. The site of anastomosis is between $3^{\text {rd }}$ and $4^{\text {th }}$ plantar metatarsal artery

Type D: 1 st and $2^{\text {nd }}$ plantar metatarsal arteries arises from deep branch of dorsalis pedis artery and $3^{\text {rd }}$ and $4^{\text {th }}$ plantar metatarsal arteries and fibular plantar marginal artery originates from lateral plantar artery. The site of anastomosis is between $2^{\text {nd }}$ and $3^{\text {rd }}$ plantar metatarsal artery

Type E: Deep branch of dorsalis pedis artery gives 1st plantar metatarsal artery and remaining all plantar metatarsal arteries and fibular plantar marginal artery is supplied by lateral plantar artery. The site of anastomosis is between $1^{\text {st }}$ and $2^{\text {nd }}$ plantar metatarsal artery. 


\section{Varalaks Rmi; Surgical Implications of Vartations and Lacation of Plantar Arterial Arch}

Type F: All the branches takes origin from lateral plantar artery. No contribution from the deep branch of dorsalis pedis artery. ${ }^{[4]}$

Considering the role of deep plantar arch and its variations in the successful outcome of any reconstructive and vascular surgeries, presents study is an attempt to learn the course, relation, variations of deep plantar arches in human cadavers.

\section{Subjects and Methods}

A total of 40 lower limbs from 20 embalmed cadavers were obtained from the department of anatomy, MVJ Medical College and Research Hospital, Bangalore, Karnataka were used for the study. The dissection of foot was carried out layer by layer. Foot with any injury, trauma and abnormalities were excluded from the study. The flexor digitorum brevis muscle was detached from its origin at calcaneum and reflected forward to expose the lateral plantar artery in the lateral aspect of foot. The oblique head of adductor hallucis muscle was dissected to observe the full course of lateral plantar artery. The dorsalis pedis artery was identified in the dorsal aspect of the foot and traced upto $1^{\text {st }}$ intermetarsal space where it gives deep plantar branch. The plantar metarsal arteries were traced and its origin was noted. The presence and origin of fibular plantar marginal arteries were also traced. The point of anastomosis between the deep branch of dorsalis pedis artery and lateral plantar artery was noted. Depending on the contribution of dorsalis pedis artery and lateral plantar artery in the origin of plantar metatarsal arteries and fibular plantar marginal artery, the arches were classified into six types as per the classification by Adachi. The findings were tabulated and percentage of each type was calculated.

In the present study topographical location of plantar arterial arch was also noted. To measure the topographical location of arch, first the length of foot was measured from the tip of second toe to posterior most part of heel using flexible ruler. Depending on the length, the foot is divided into 3 equal parts- Anterior, Middle and posterior. In the majority of foot as the arch is usually located in the middle part, to know the exact location, the middle part is again divided into three equal parts- anterior middle (AM), intermediate middle (IM), posterior middle (PM). Pins were used to mark the border of middle subdivisions. Zone in which arch located was noted down and percentage of each location is calculated.

\section{Results}

The total 40 lower limbs were studied. The deep plantar arch was present in all 40 lower limbs.

The results were tabulated and analysed statistically.

The arches were classified into 6 types. In the present study it was observed that Type $\mathrm{C}$ was the most predominant type followed by type D. Type A which was formed mainly by dorsalis pedis artery was absent. Type B was the least common type seen in $10 \%$ of specimens.

\begin{tabular}{|c|c|c|c|c|c|}
\hline Type of arch & Branching pattern & Right & Left & Total & Percent-age \\
\hline Type A & 1-4 Plantar metatarsal and fibular plantar marginal artery from dorsalis pedis artery & - & - & - & - \\
\hline Type B & $\begin{array}{l}\text { 1-4 Plantar metatarsal arteries from dorsalis pedis artery and fibular plantar marginal } \\
\text { artery from Lateral plantar artery. }\end{array}$ & 2 & 2 & 4 & 10 \\
\hline Type C & $\begin{array}{l}\text { 1-3 Plantar metatarsal arteries from dorsalis pedis artery and 4th Plantar metatarsal ad } \\
\text { fibular planatar marginal artery from Lateral plantar artery }\end{array}$ & 5 & 8 & 13 & 32.5 \\
\hline Type D & $\begin{array}{l}\text { 1-2 Plantar metatarsal arteries from dorsalis pedis artery and 3rd, 4th Plantar metatarsal } \\
\text { and fibular plantar marginal artery from Lateral plantar artery }\end{array}$ & 6 & 5 & 11 & 27.5 \\
\hline Type E & $\begin{array}{l}\text { 1st Plantar metatarsal arteries from dorsalis pedis artery and 2nd, 3rd, 4th Plantar } \\
\text { metatarsal ad fibular plantar marginal artery from Lateral plantar artery }\end{array}$ & 4 & 3 & 7 & 17.5 \\
\hline Type F & 1-4 Plantar metatarsal and fibular plantar marginal artery from lateral plantar artery & 3 & 2 & 5 & 12.5 \\
\hline
\end{tabular}

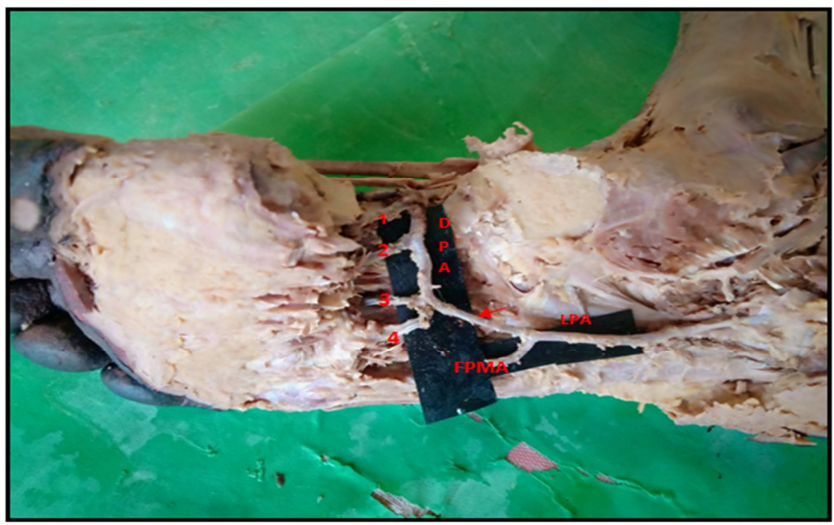

Figure 1: Type B plantar arterial arch.1-4 plantar metatarsal artery takes origin from deep branch of dorsalis pedis artery (DPA) and fibular plantar marginal artery(FPMA) arising from lateral plantar artery.(LPA)

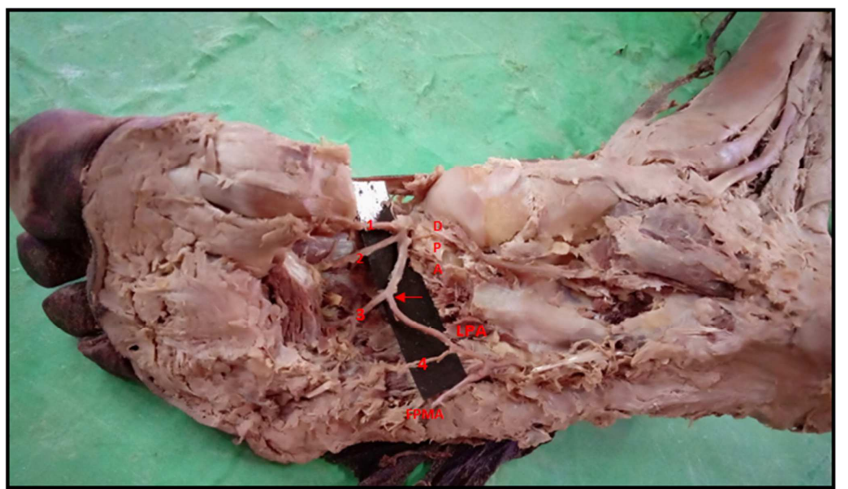

Figure 2 :Type $\mathrm{C}$ plantar arterial arch: 1-3 plantar metatarsal arteries takes origin from deep branch of dorsalis pedis artery (DPA) and 4th plantar metatarsal artery and fibular plantar marginal artery(FPMA) arising from lateral plantar artery.(LPA). 


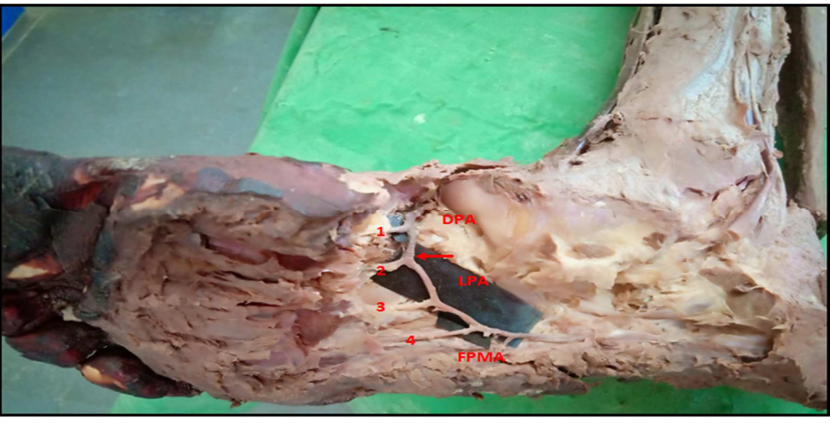

Figure 3: Type D plantar arterial arch: 1-2 plantar metatarsal arteries takes origin from deep branch of dorsalis pedis artery (DPA) and rd and 4th plantar metatarsal artery and fibular plantar marginal artery(FPMA) arising from lateral plantar artery.(LPA).

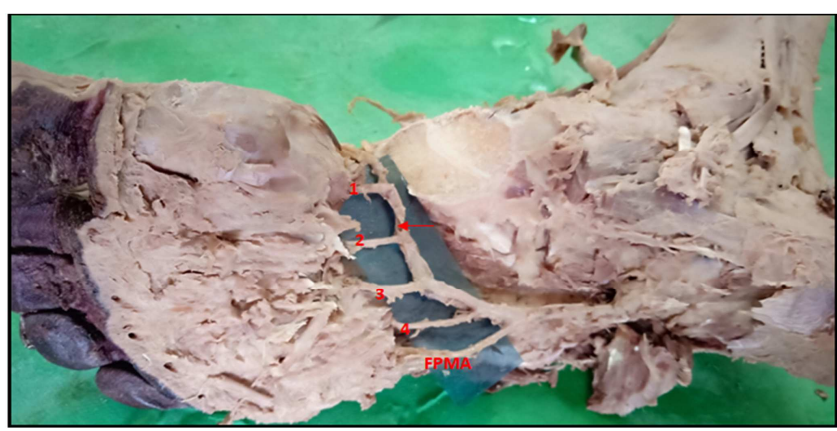

Figure 4: Type E plantar arterial arch: 1st plantar metatarsal artery takes origin from deep branch of dorsalis pedis artery (DPA) and 2nd to 4th plantar metatarsal artery and fibular plantar marginal artery(FPMA) arising from lateral plantar artery.(LPA).

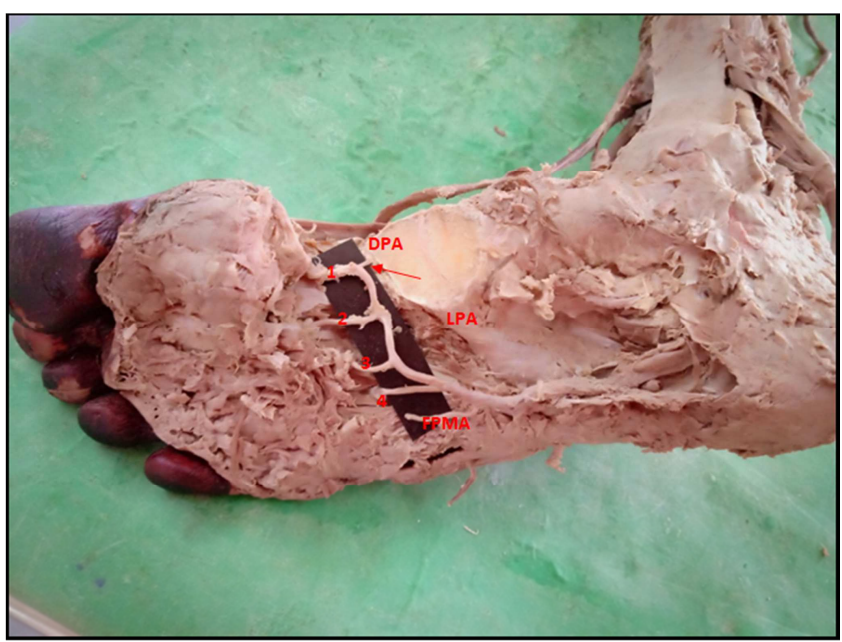

Figure 5: Type $\mathbf{F}$ plantar arterial arch: All plantar metatarsal arteries and fibular plantar marginal artery arising from lateral plantar artery(LPA).

Table 2: Topographical location of plantar arterial arch

\begin{tabular}{|l|l|l|l|l|}
\hline Location & Right & Left & Total & Percentage \\
\hline Anterior middle & 7 & 10 & 17 & 42.5 \\
\hline $\begin{array}{l}\text { Junction } \\
\text { between }\end{array}$ & 8 & 6 & 14 & 35 \\
$\begin{array}{l}\text { Anterior middle } \\
\text { \&Intermediate } \\
\text { middle }\end{array}$ & & & & \\
\hline $\begin{array}{l}\text { Intermediate } \\
\text { middle }\end{array}$ & 5 & 4 & 9 & 22.5 \\
\hline
\end{tabular}

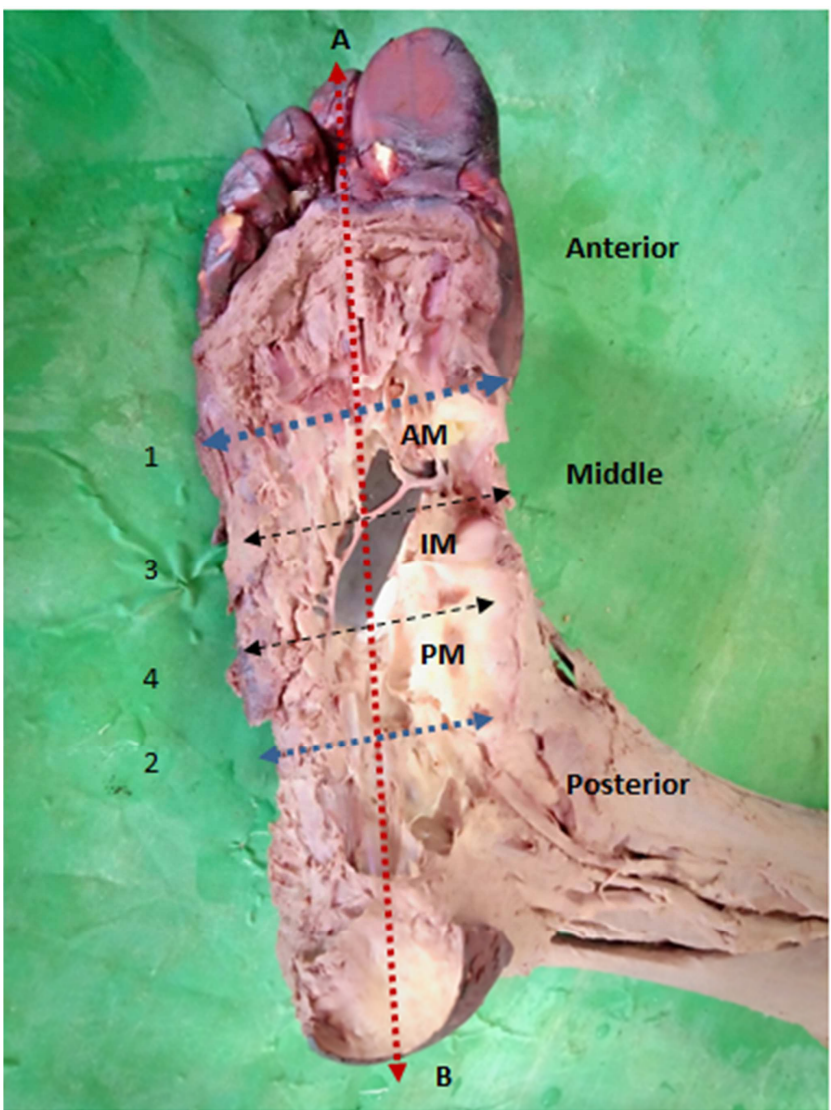

Figure 6: Schematic diagram showing the topographical location of plantar arterial arch (vertical line AB: length of foot measured from tip of second toe to posterior most part of heel Line 1 and 2: Dividing the foot into 3 equal parts. Line 3 and 4: Dividing the middle one third of foot into Anterior middle(AM),Intermediate middle(IM) and Posterior middle(PM)

\section{Discussion}

Table 3: Comparisons of different types of deep plantar arch of present study with the other studies.

\begin{tabular}{|l|l|l|l|l|}
\hline $\begin{array}{l}\text { Type of } \\
\text { deep } \\
\text { plantar } \\
\text { arch }\end{array}$ & $\begin{array}{l}\text { Adachi } \\
\mathbf{1 0 3} \\
\text { feet) }\end{array}$ & $\begin{array}{l}\text { Kalicharan } \\
\text { (40 feet)9 }\end{array}$ & $\begin{array}{l}\text { Anupama } \\
\text { (50 feet) }\end{array}$ & $\begin{array}{l}\text { Present } \\
\text { study(40 } \\
\text { feet) }\end{array}$ \\
\hline Type A & $25.3 \%$ & $25 \%$ & $10 \%$ & -- \\
\hline Type B & $32.3 \%$ & $5 \%$ & $4 \%$ & $10 \%$ \\
\hline Type C & $14.6 \%$ & $20 \%$ & $26 \%$ & $32.5 \%$ \\
\hline Type D & $14.6 \%$ & $24 \%$ & $36 \%$ & $27.5 \%$ \\
\hline Type E & $6.1 \%$ & $10 \%$ & $20 \%$ & $17.5 \%$ \\
\hline Type F & $7 \%$ & $21 \%$ & $4 \%$ & $12.5 \%$ \\
\hline
\end{tabular}

Human feet are the only part of the body which supports the entire body weight during locomotion. This main task of foot to support the entire body ,is maintained mainly by its blood supply which is contributed by deep plantar arch. ${ }^{[5]}$ Although the previous studies have mentioned about arterial anatomy of the foot in literature, more detailed studies of the deep plantar arch and its branches in terms of morphological and morphometric variations are still insignificant. ${ }^{[6]}$

Adachi conducted an extensive study on 103 feet and classified the arches into six types (A-E) based on the origin 
of plantar metatarsal arteries and fibular plantar marginal artery. The present study has used same classification.

In the present study type $\mathrm{C}$ was more common and type $\mathrm{A}$ was absent. Adachi et al observed type B as the most predominant pattern whereas study by Kalicharan et al noted type A and Anupama et al Type D as the common pattern. The results of each studies is unique, not correlating with each other. Since the embryonic development of arterial system is complex, it is not unusual to observe anatomical variations. Absence of plantar arterial arch was noted in a study by Bergman et al. In their study blood supply to the foot was absent and plantar arch was replaced by posterior tibial artery. Rare cases where posterior tibial artery was absent, peroneal artery itself divided into medial and lateral plantar artery to compensate the vascular supply to the foot. The same study also showed a case of double plantar arterial arch. Such variations were not observed in the present study. ${ }^{[10]}$

Due to modern life style changes, present population is commonly exposed to diseases like diabetes mellitus and hypertension. One of the complications of diabetes as well as non-diabetic atherosclerotic diseases is ischemia of foot ending with amputation of foot as the line of treatment. Knowledge of origin of plantar metatarsal arteries is important to know the amount of damage of tissues, in case if all the plantar metatarsal arteries arises from either dorsalis pedis artery or lateral plantar artery then occlusion of these arteries will lead to extensive tissue damage. ${ }^{[11]}$

Because of the advances of microvascular surgeries, the frequency of amputations can be reduced by bypass surgeries .O'Brien et al was the first one to use dorsalis pedis artery as the neurovascular flap in vascular surgeries. ${ }^{[12]}$ It can also be used as island flap to cover the ankle or heel defects and as a free flap for palm defects. Its easy availability because of its superficial location in the dorsal aspect, its medium caliber and the absence of collateral branches makes it ideal graft material for bypass surgeries. Hence the knowledge of morphological variations of deep plantar arch is important to surgeons while performing amputation of forefoot. ${ }^{[7]}$ The course of these arteries can be taken as a landmarks in surgical procedures or dealing with biomechanics of foot. Pre-operative angiography and contrast enhanced magnetic resonance will help to identify the site of occlusion as well as to reduce the complication s during surgical interventions. Knowledge of plantar arterial arch, its variable anastomotic pattern with deep plantar artery helps the plastic surgeons while harvesting the great toe or second toe to reconstruct damaged thumb or index finger. ${ }^{[13]}$

In the present study, $42.5 \%$ of fee arch is located in the anterior middle, ${ }^{[17]} 35 \%$ in the junction between anterior middle \& intermediate middle and $22.5 \%$ in the intermediate middle region. ${ }^{[9,14]}$

In a study by Kalicharan et al (40 feet), $90 \%$ of arches were located in the anterior middle and 10\% in the junction between anterior middle and intermediate middle.

Gabrielli et al (50 feet) found $90 \%$ arches in the anterior middle and $8 \%$ in the junction between anterior middle and intermediate middle, $2 \%$ in intermediate middle region. ${ }^{[1]}$ In a study by Ozer (50 feet), $62 \%$ in the intermediate middle, $20 \%$ in the junction between intermediate middle
$\&$ Posterior middle and $18 \%$ in the posterior middle. Farlex et al in the similar study stated that the arches are located within the transverse arch of foot. Knowledge of position of plantar arterial arch is crucial to surgeons while performing amputation of the forefoot or using the course of the artery as a landmark in surgical procedure and dealing with biomechanics of the foot. ${ }^{[7-9]}$ Pseudoaneurysm of lateral or medial plantar artery is one of the common complication observed in majority of surgeries involving the foot which can be minimized if the topographic location of arches were known prior to the surgeries. ${ }^{[14]}$

\section{Conclusion}

In the present study conducted on 40 specimens type $\mathrm{C}$ arch was more predominant and type A arch was absent. Majority of arches were located in the anterior middle portion of foot. Thorough knowledge of blood supply to the foot as well as its topographical location is essential for reconstructive surgeons in the mobilization and application of plantar flaps, while harvesting the great toe or second toe to reconstruct damaged thumb or index finger. Anatomical knowledge of plantar arterial arch is also important for microvascular surgeons to perform arterial bypass grafting to prevent ischemic necrosis. Pre-operative angiography and contrast enhanced magnetic resonance will help to identify the site of occlusion as well as to reduce the complication $s$ during surgical interventions.

\section{References}

1. Gabrielli C, Olave E, Mandiola E, Rodrigues CFS, Prates JC. The plantar arch in humans, Constitution ad topography. Surgical radiological anatomy .2001,23(04):253-58.

2. Datta AK. Part 1. Superior and inferior extremities In: Datta AK, eds. Essentials of Human Anatomy. 5th ed. Kolkata: Current Books International; 2009: 2.14-215

3. Anupama K ,Saraswathi G, Shetty S.A study of plantar arterial arch with its surgical perspective. International Journal of anatomy and research .2016,4(02):2392-96.

4. Sarafian SK. Anatomy of the foot and ankle-Descriptive, topographic, functional. JB. Lippincott company.Philadelphia;1983: 281-91.

5. Anupama K, Saraswathi G, Jyothi KC, Shanmuganathan K. A study of fibular plantar marginal artery with its clinical perspective. International journal of current research and review. March 2014,06(06):71-74.

6. Krasteva E,NovaKov S.Anatomical study of arterial plantar arch and its clinical significance.Acta morphologica et anthropologica.2018,25(3-4):121-27.

7. Bergman RA, Thomson SA,Afifi AK,MSR Miyauchi.Various arterial patterns on the dorsum of foot and in the plantar arch.Anatomy atlases.An anatomy digital library.Illustrated encyclopedia of human anatomic variations:Opus II:cardiovascular system.Available at http://www.anatomyatlases.org/anatomic variants/cardiovascular/text/arteries/dorsalis pedis.shtml.

8. Hughes $\mathrm{K}$, Domenig $\mathrm{CM}$, Hamdan $\mathrm{AD}$, Schermerhorn $\mathrm{M}$, Aulivola B, Blattman S et al .Bypass to plantar and tarsal arteries: An acceptable approach to limb salvage .Journal of vascular surgery.2004;40:1149-57.

9. Strauch B, Sharzer LA, Brauman D. Innervated free flap for sensitivity and coverage, Chapter 14 in microsurgery for major limb reconstruction. Urbaniak JR. Mosby publication;1990:11216.

10.Papon X, Brillu C, Fournier HD, Hentati N, Mercier PH. 


\section{Varalakshmi; Surgical Implications of Variations and Lacation of Plantar Arterial Arch}

Anatomic study of deep plantar artery: Potential by-pass receptor site. Surgical and radiological anatomy.(1998);20:263-266.

11. Kalicharan A, Pillay P, Rennie C, Haffajee MR. The anatomy of plantar arterial arch. International journal of morphology .2015;18(06):36-42.

12. Sebastien C, Douek P, Moulin P, Vaudoux M, Marchand B. Contrast enhanced MR Angiography of the foot: Anatomy and clinical application in patients with diabetes .American Journal of radiology.2004;182:1435-1442.
13. Ozer MA, Govsa F, Bilge O. Anatomic study of the deep plantar arch. Clinical anatomy. 2005;18(06): 434-442.

14. Farlex. Deep plantar (arterial) arch. The free dictionary, Farlex, 2014. Available in: http://medical-dictionary.the free dictionary.com/deep+plantar+(arterial)+arch.

15. Tonogai I, Hayashi F, Sairyo K. Distances from the deep plantar arch to lesser metatarsals at risk during osteotomy: A fresh cadaveric study. Journal of foot and ankle research.2018;57:11

Copyright: ( $\odot$ the author(s), publisher. Academia Anatomica International is an Official Publication of "Society for Health Care \& Research Development". It is an open-access article distributed under the terms of the Creative Commons Attribution Non-Commercial License, which permits unrestricted non-commercial use, distribution, and reproduction in any medium, provided the original work is properly cited.

How to cite this article: Varalakshmi KL, Afroze M KH, Sangeeta M. Surgical Implications of Variations and Location of Plantar Arterial Arch: An Anatomical Study. Acad. Anat. Int. 2019;5(2):95-99.

DOI: dx.doi.org/10.21276/aanat.2019.5.2.25

Source of Support: Nil, Conflict of Interest: None declared. 